\title{
Sex differences in play behavior in juvenile tufted capuchin monkeys (Cebus apella)
}

\author{
Annika Paukner ${ }^{*}$ and Stephen J. Suomi \\ Laboratory of Comparative Ethology National Institute of Child Health and Human Development NIH \\ Animal Center PO Box 529 Poolesville, MD 20837 USA
}

\section{Abstract}

According to the motor training hypothesis, play behavior in juvenile primates improves motor skills that are required in later adult life. Sex differences in juvenile play behavior can therefore be expected when adult animals assume distinct sexually dimorphic roles. Tufted capuchin monkeys show sexually dimorphic levels of physical antagonism in both inter- and intragroup encounters. Accordingly, it can be predicted that juvenile capuchins also show sex differences in social play behavior. To test this hypothesis, the play behavior of nine juvenile and two infant capuchins was examined. As predicted, juvenile males showed significantly higher levels of social play (wrestle, chase) than juvenile females, but no differences were found in nonsocial play (arboreal, object). Levels of infant play behavior were comparable to that of juveniles. These results lend support to the motor training hypothesis and highlight the need for more detailed investigations of individual differences in play behavior.

\section{Keywords}

Capuchin monkey; Cebus apella; social play; nonsocial play; motor training hypothesis

\section{Introduction}

There is no doubt that play is a widespread behavior in many species including mammals, birds, and reptiles (Fagen, 1981). Play behavior can be broadly classified as social play (involving other individuals) or nonsocial play (involving objects or locomotor play). According to the motor-training hypothesis (Byers \& Walker, 1995), play behavior trains motor skills that have an immediate and / or deferred beneficial effect on an individual's physiology. Consequently, sex differences in play behavior can be expected in species in which male and female adults show differential behavioral characteristics. For example, if there are higher frequencies of fighting behaviors in adult males than in adult females, it can be expected that males will also show more play fighting behavior as juveniles. On the other hand, if skills are used by both sexes to the same extent (such as predator avoidance), play behavior potentially beneficial for such a skill might be equally expressed by juveniles of both sexes.

Rhesus macaques, for example, assume distinct sexually dimorphic behaviors as adults. Females are the main caretakers of infants and maintain group cohesiveness through affiliative grooming. By contrast, males aggressively defend the troop from other males and predators. Not surprisingly, male rhesus juveniles show significantly more play fighting behaviors than females (Lovejoy \& Wallen, 1988). As a proximal cause, levels of prenatal androgen have

\footnotetext{
*corresponding author Tel. +1 3014431053 Fax +1 3014960630 Email pauknera@mail.nih.gov
} 
been linked to social play during the juvenile period (Wallen, 1996) and the expression of social play appears surprisingly unaffected by differences in complexity of the social rearing environment (Harlow, 1962).

Tufted capuchin monkeys (Cebus apella) are a New World primate species that live in multimale/multi-female groups (Fragaszy et al., 2004). Even though females may emigrate (Izar, 2004), it is usually the males who leave their natal groups during their juvenile period (Robinson \& Janson, 1987). Males continue to change between social groups as adults ca. every 4 years, usually resulting in aggressive fights with resident adult males (Fragaszy et al., 2004). In intergroup encounters, adult females seldom actively participate in the group's defense. Even within groups, females are more likely to express conflicts via threats whereas males are more likely to resort to physical antagonism (Fragazsy et al., 2004).

Based on the differential antagonistic behavior of adult capuchins, it may be predicted that juvenile males express more social play behavior (such as wrestling and chasing other individuals) than juvenile females. In the present study, we examined the play behavior of captive juvenile capuchin monkeys and predicted sex differences in social play, but not nonsocial play. We also collected data on the play behavior of two male infants. Even though data from these animals are not suitable for testing the motor training hypothesis in the present context, they provide some interesting observations regarding the developmental course of play behavior.

\section{Methods}

Subjects

Subjects were 5 male and 4 female juvenile capuchin monkeys as well as 2 male infants (Cebus apella; see Table 1 for details). All subjects were captive born and were part of a larger breeding group housed at the NIH Animal Center, Poolesville, MD, in a large outdoor enclosure (ca. $250 \mathrm{~m}^{3}$ ), enriched with perches, ladders, swings and several plastic and metal manipulanda. In addition to the juveniles, the group comprised 10 adults ( 3 male and 7 female, $5+$ years old). A further 2 infants were born into the group during the course of the study. Water and commercial monkey biscuits were available ad libitum. Additional supplements of seeds and fresh fruits or nuts were given daily. Monkeys were not food-deprived for this study.

\section{Procedure}

Data were collected between May and September 2007. Animals were observed 6 times a week in 5 minute focal observation sessions in random order, half of them conducted in the morning $(9 \mathrm{am}-11 \mathrm{am})$ and half in the afternoon $(3 \mathrm{pm}-5 \mathrm{pm})$. Data were collected using the Pocket Observer (PDA HP iPAQ Pocket PC hx2190 and The Observer 5.0, Noldus). We scored the durations of all social and nonsocial play behavior. Social play included wrestling with and chasing/being chased by one or more other animals. Nonsocial play included object play, defined as oral or manual exploration of any metal or plastic manipulanda that were provided as part of their normal enrichment program. Manipulations of food items, bedding, or parts fixed of the enclosure were not scored as object play. The second category of nonsocial play was arboreal play, defined as quick, acrobatic and/or exaggerated locomotion (including somersaults, swinging from own tail etc.). The total observation time was $132 \mathrm{~h}, 12 \mathrm{~h}$ per individual.

\section{Results}

Juveniles spent a total of $12 \mathrm{~h} 8 \mathrm{~min}$ and $30 \mathrm{sec}$ playing, or $9.2 \%$ of the observation time. Broken down by gender, males played on average $1 \mathrm{~h} 45 \mathrm{~min}(14.6 \%)$ and females played on average 
51min (7.09\%). Males, but not females, exhibited more social than nonsocial play (Fig. 1). Using nonparametric Mann-Whitney tests, there were no differences between males and females in the duration of object play $(Z=0.01, p>0.05)$ or arboreal play $(Z=-0.74, p>0.05)$. Males spent significantly more time in wrestle play $(\mathrm{Z}=-2.449, \mathrm{p}=0.016)$ and chase play $(\mathrm{Z}=$ $-2.449, \mathrm{p}=0.016$ ) than females.

The infant males spent a combined total of $3 \mathrm{~h}$ in play, or $12.5 \%$ of observation time. Similar to juvenile males, infants spent most time in wrestle play (45.61\%), followed by object play $(39.8 \%)$, arboreal play (10.04\%), and chase play (4.55\%; Table 1$)$.

\section{Discussion}

Male juvenile capuchins engaged in social play for significantly longer periods of time than female juvenile capuchins. No differences in durations of nonsocial play were found. These results are in line with the motor-training hypothesis, and further support the view that there is a connection between play behavior during the juvenile period and behavioral characteristics during later adult life.

The obtained results contrast with previous studies that failed to find significant sex differences in capuchin play behavior (Visalberghi \& Guidi, 1998; Fragaszy et al., 2004). Several factors are known to affect the expression of play behavior, including availability of play mates, availability of food, and size and type of enclosure (Visalberghi \& Guini, 1998; Byrne \& Suomi, 1996; Fagen, 1993). The relatively large number of available play partners as well as large, open spaces might have particularly favored the expression of social play in the current study. In addition, study animals in the current study were mostly in their mid- to late-juvenility, a period that is known to be related to peak levels of play behavior. It should also be noted that even though differences between male and female juveniles failed to reach statistical significance in previous studies, males nonetheless appeared to play more frequently than females (Visalberghi \& Guidi, 1998; Fragaszy et al., 2004; Welker et al., 1989).

Capuchins in captivity usually show higher rates of play than animals in the wild (Fragaszy et al., 2004). This difference is most likely connected to the already mentioned negative association of play behavior with the level at which nutritional demands are being met as well as other demands on the time budget of capuchins in the wild (e.g., time spent travelling). Nevertheless we have probably underestimated the amount of time capuchins played with objects in the present study since we excluded any manipulations of food items or bedding (a source of potentially ingestible items) from object play. The reason for this precaution was to avoid any potential confound of foraging behaviors with play behaviors which may look very similar, especially in young capuchins (Fragaszy et al., 2004). Capuchins frequently manipulated food items in a playful manner such as banging them on the floor, rubbing them between their palms, or passing them back and forth between wire mesh before either eating them in whole or in part, or discarding them (pers. obs.).

The two infant capuchins played for a similar percentage of their time budget as older juveniles, and spent approximately equal amounts of time in social and nonsocial play. The developmental course of play behavior in capuchins has been described in several studies (Fragaszy, 1989; Fragaszy et al., 1991; Byrne \& Suomi, 1998). Infant capuchins first preferentially engage in locomotor and object play, starting at the same time as they first spend time away from their mothers (ca. 8 weeks old; Fragaszy et al., 1991). At ca. 12 weeks old, the first social play bouts are observed (Fragaszy, 1989). As with juveniles, environmental factors may affect infants' play, but other infant-specific factors may also be important. For example, physical and emotional dependency on their mothers might affect the expression of play behavior, and might also interact with other environmental factors. In the present study, both 
infants were physically independent from their mothers (both infants' mothers gave birth during the course of the study), but appeared to spend much of their time in proximity to them (pers.obs.). Individual differences in play behavior in infant and juvenile primates as well as the relationship between expression of play behavior in the juvenile period and the level of skill competence in later life continue to be important subjects of further investigation.

\section{Acknowledgements}

This study was supported by funds from the Division of Intramural Research, NICHD. This research complied with the Animal Welfare Act and was approved by the National Institute of Child Health and Human Development Animal Care and Use Committee.

\section{References}

Byers JA, Walker C. Refining the motor training hypothesis of play. Am Nat 1995;146:25-40.

Byrne G, Suomi SJ. Individual differences in object manipulation in a colony of tufted capuchins. J Hum Evol 1996;31:259-267.

Byrne G, Suomi SJ. Relationship of early infant state measures to behavior over the first year of life in the tufted capuchin monkey (Cebus apella). Am J Primatol 1998;44:43-56. [PubMed: 9444322]

Fagen, R. Animal play behaviour. Oxford University Press; New York: 1981.

Fagen, R. Primate juveniles and primate play. In: Pereira, ME.; Fairbanks, LA., editors. Juvenile primates: life history, development, and behavior. Oxford University Press; New York: 1996. p. 182-196.

Fragaszy DM. Activity states and motor activity in an infant capuchin monkey (Cebus apella) from birth through eleven weeks. Dev Psychobiol 1989;22:141-157. [PubMed: 2925002]

Fragaszy DM, Baer J, Adams-Curtis L. Behavioral development and maternal care in tufted capuchins (Cebus apella) and squirrel monkeys (Saimiri sciureus) from birth through seven months. Dev Psychobiol 1991;24:375-393. [PubMed: 1783220]

Fragaszy, DM.; Visalberghi, E.; Fedigan, LM. The complete capuchin. Cambridge University Press; Cambridge: 2004.

Harlow HF. The heterosexual affectional system in monkeys. Am Psychol 1962;17:1-9.

Izar P. Female social relationships of Cebus apella nigritus in southeastern Atlantic Forest: an analysis through ecological models of primate social evolution. Behaviour 2004;141:71-99.

Lovejoy J, Wallen K. Sexually dimorphic behavior in group-housed rhesus monkeys (Macaca mulatta) at 1 year of age. Psychobiol 1988;16:348-356.

Robinson, JG.; Janson, CH. Capuchins, squirrel monkeys and atelines: socioecological convergence with Old World primates. In: Smuts, BB.; Cheney, DL.; Seyfarth, RM.; Wrangham, RW.; Struhsaker, TT., editors. Primate Societies. University of Chicago Press; Chicago: 1987. p. 69-82.

Visalberghi E, Guidi C. Play behaviour in young tufted capuchin monkeys. Folia Primatol 1998;69:419422. [PubMed: 9885350]

Wallen K. Nature need nurture: the interaction of hormonal and social influences on the development of behavioral sex differences in rhesus monkeys. Horm Behav 1996;30:364-378. [PubMed: 9047263]

Welker C, Höhmann H, Schäfer-Witt C. Zur Ontogenese der Geschlechterrollen bei dem gehaubten Kapuziner Cebus apella (Ontogeny of sex roles in the black-capped capuchin Cebus apella). Homo 1989;39:26-34. 


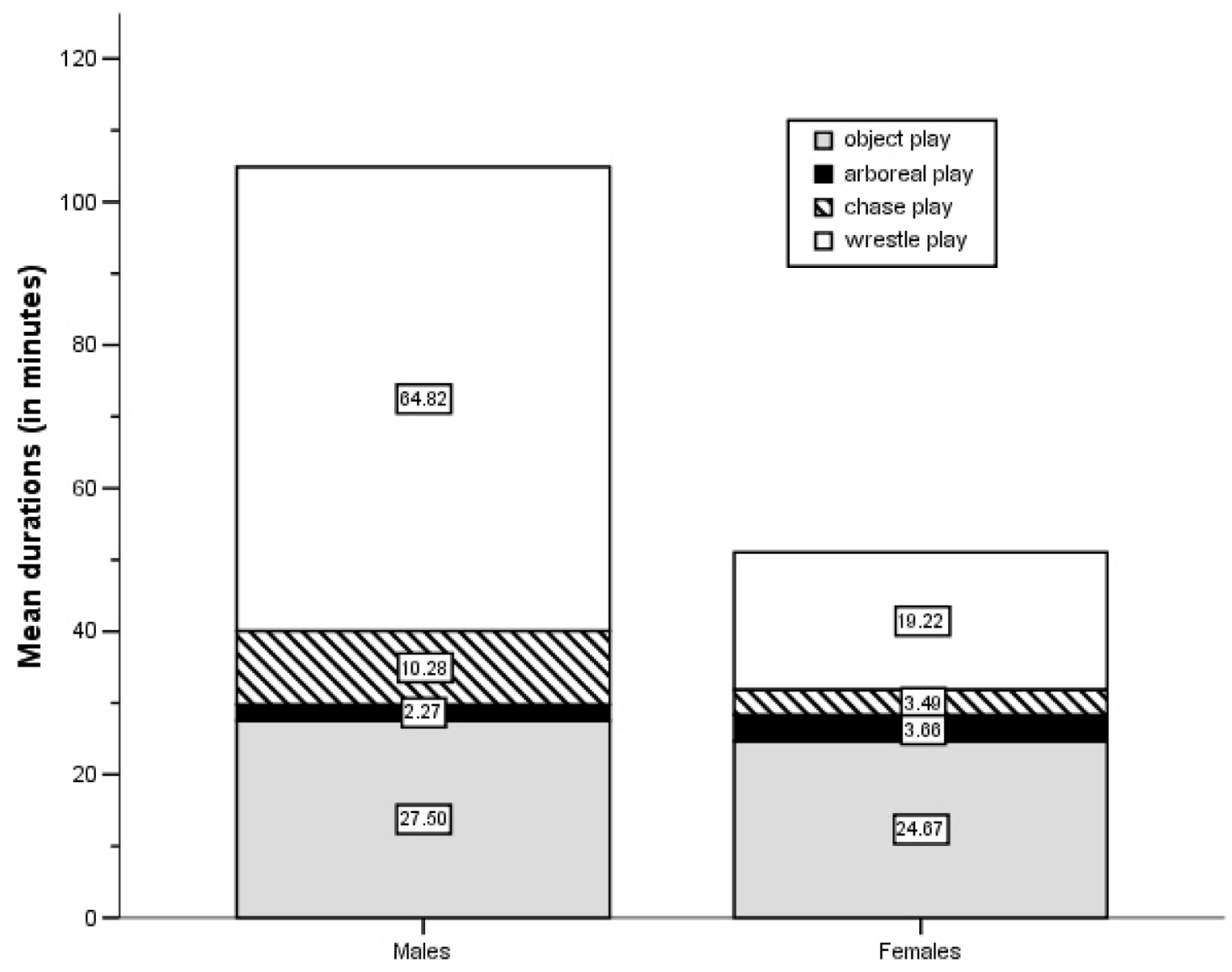

Figure 1.

Average durations (in minutes) of observed play behaviors for male and female juveniles. 


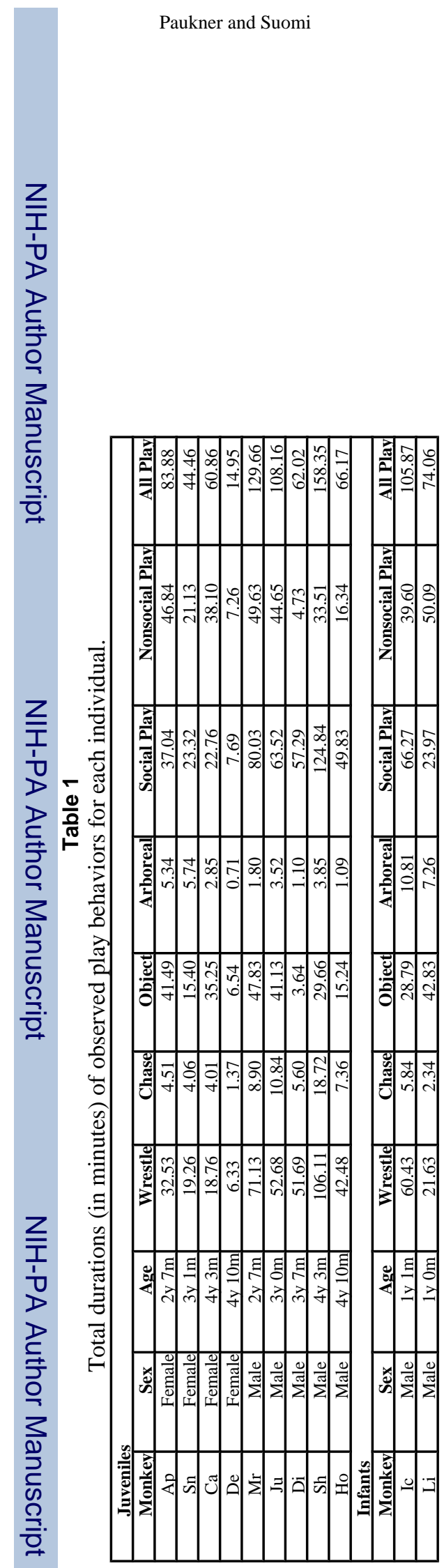

Primates. Author manuscript; available in PMC 2009 October 1. 